\title{
Intravenous Alcohol Self-Administration in the P Rat
}

\author{
Kyle A. Windisch, Ann E. K. Kosobud, and Cristine L. Czachowski \\ Department of Psychology, Indiana University - Purdue University, Indianapolis, Indiana 46202
}

\section{Abstract}

Alcohol consumption produces a complex array of effects that can be divided into two types: the explicit pharmacological effects of ethanol (which can be temporally separate from time of intake) and the more temporally "relevant" effects (primarily olfactory and taste) that bridge the time from intake to onset of the pharmacological effects. Intravenous (IV) self-administration of ethanol limits the confounding "non-pharmacological" effects associated with oral consumption, allows for controlled and precise dosing, and bypasses first order absorption kinetics, allowing for more direct and better-controlled assessment of alcohol's effect on the brain. IV ethanol selfadministration has been reliably demonstrated in mouse and human experimental models; however, models of IV self-administration have been historically problematic in the rat. An operant multiple-schedule study design was used to elucidate the role of each component of a compound IV-ethanol plus oral-sucrose reinforcer. Male alcohol-preferring P rats had free access to both food and water during all IV self-administration sessions. Animals were trained to press a lever for orally delivered $1 \%$ sucrose (1S) on a fixed ratio 4 schedule, and then surgically implanted with an indwelling jugular catheter. Animals were then trained to respond on a multiple FR4-FR4 schedule composed of alternating 2.5-min components across 30-min sessions. For the multiple schedule, two components were used: an oral 1S only and an oral 1S plus IV $20 \%$ ethanol $(25 \mathrm{mg} / \mathrm{kg} /$ injection). Average total ethanol intake was $0.47 \pm 0.04 \mathrm{~g} / \mathrm{kg}$. We found significantly higher earning of sucrose-only reinforcers and greater sucrose-lever error responding relative to the compound oral-sucrose plus IV-ethanol reinforcer. These response patterns suggest that sucrose, not ethanol, was responsible for driving overall responding. The work with a compound IV ethanol-oral sucrose reinforcer presented here suggests that the existing intravenous ethanol self-administration methodology cannot overcome the aversive properties of ethanol via this route in the rat.

\section{Keywords}

alcohol-preferring; multiple schedule; conflict

(C) 2014 Elsevier Inc. All rights reserved.

Address correspondence to: Cristine L. Czachowski, Department of Psychology, Indiana University - Purdue University, 402 N. Blackford St. LD124, Indianapolis, IN 46202, Telephone: +1 317278 4820, Fax: +1 317274 6756, cczachow @iupui.edu.

Conflicts of interest: none declared

Publisher's Disclaimer: This is a PDF file of an unedited manuscript that has been accepted for publication. As a service to our customers we are providing this early version of the manuscript. The manuscript will undergo copyediting, typesetting, and review of the resulting proof before it is published in its final citable form. Please note that during the production process errors may be discovered which could affect the content, and all legal disclaimers that apply to the journal pertain. 


\section{Introduction}

Alcohol is a multifaceted drug with a complex array of effects resulting from consumption. The principle effects of alcohol consumption can be divided into the more temporally relevant orosensory effects and the later onset direct pharmacological effects of ethanol. Intravenous (IV) self-administration provides a method by which these distinct effects can be isolated to assess their component properties relevant to the reinforcing effects of alcohol. IV ethanol self -administration has been successfully implemented in mice (Blokhina, Dravolina, Bespalov, Balster, \& Zvartau, 2004; Grahame \& Cunningham, 1997; Grahame, Low, \& Cunningham, 1998), monkeys (Karoly, Winger, Ikomi, \& Woods, 1978; Williams, Broadbear, \& Woods, 2004), and humans (Zimmermann et al., 2009; Zimmermann et al., 2008). Although IV ethanol self-administration lacks the face validity of the more commonly used oral administration route, it allows for more precise control of the neural exposure resulting from each reinforcer dose since venous administration of ethanol bypasses digestive tract absorption, resulting in a more rapid brain exposure. Additionally, utilization of the IV route allows for precise standardization of ethanol exposure for each individual reinforcer dose across animals. Overall, IV ethanol administration allows for a faster brain exposure of ethanol in precisely controlled doses across subjects; however, selfadministration by this route has been problematic in the rat.

Mice have been shown to self-administer IV ethanol at relatively elevated ethanol concentrations [15-25\%; (Grahame \& Cunningham, 1997)]. Mice have also been shown to develop a conditioned place preference (CPP) for experimenter-delivered IV ethanol [30\% ethanol (v/v), $3.4 \mu \mathrm{L} / \mathrm{min}$ infusion during two 25-min ethanol infusions in non-preferred compartment, cumulative IV ethanol dose $0.82 \pm 0.015 \mathrm{~g} / \mathrm{kg} / \mathrm{day}$ ] (Kelley, Bandy, \& Middaugh, 1997). Several significant drawbacks have been noted with intravenous selfadministration in mice. Indwelling catheterization surgeries are relatively arduous with mice and have a decremented catheter longevity compared with other animals (Thomsen \& Caine, 2007). In contrast, rat catheterization surgeries are relatively simple and have a longer patency than mice (lasting on average 8-14 weeks when properly implanted and maintained). As well, rats tend to have more stable responding for intravenous drug administration compared to mice (Thomsen \& Caine, 2007).

However, the development of successful experimental models of intravenous ethanol selfadministration remains elusive in rats. Studies using non-deprived rats have shown exceedingly low ethanol intake (Gass \& Olive, 2007; Lyness \& Smith, 1992; Sinden \& Le Magnen, 1982; Smith \& Davis, 1974). The low ethanol intake observed in these studies may be partially attributable to the low ethanol infusate concentrations used $(0.25-4 \%)$ and subsequent low unit doses $(0.12-8 \mathrm{mg} / \mathrm{kg} /$ infusion). Although food deprivation (Oei \& Singer, 1979) and experimenter-administered high doses of ethanol (Numan, 1981) result in elevated levels of subsequent ethanol self-administration, these methods are significantly different from the conditions of human alcohol misuse and dependence. Such experimentercontrolled manipulations allow for neither the examination of the underlying motivation to consume high levels of alcohol nor the neurological underpinnings of human alcohol addiction. Escalated IV ethanol self-administration has also been demonstrated when rats have either previous or concurrent exposure to other drugs of abuse, such as cocaine 
(Ikegami et al., 2002) or heroin (Hyytiä, Schulteis, \& Koob, 1996). However, such studies similarly fail to answer questions relevant to human alcohol abuse.

Previous attempts to establish IV ethanol self-administration in rats have predominately utilized outbred lines (e.g., Wistar, Long-Evans, and Sprague-Dawley). These outbred lines typically do not readily acquire oral ethanol self-administration without the use of various techniques (e.g., sucrose fading, limited access, liquid diet, and food restriction) to facilitate acquisition. The noted exception is a study by Hyytiä et al. (1996) using the selected alcohol-preferring AA and alcohol-avoiding ANA rat lines with IV ethanol selfadministration. This study manipulated ethanol dose by changing the duration of the pump action. As dose increased (from 1-4 mg/kg/infusion), responding in the ANAs decreased and responding in the AAs decreased and then stabilized. It is therefore possible that the increasing cumulative infusate volume may have contributed to limiting total ethanol intake despite the use of a selected alcohol-preferring rat line. This suggests that it may be possible to maximize the potential for acquisition of IV ethanol responding by using a rat line selected for alcohol intake, combined with a higher concentration of ethanol infusate, similar to those used in mouse studies [approximately 15-25\% ethanol, 60-90 mg/kg/infusion (Grahame \& Cunningham, 1997; Grahame et al., 1998)] that have successfully demonstrated IV ethanol self-administration. This would maximize the potential for acquisition of IV ethanol responding while minimizing physiological strain due to elevated total infused volume.

Several rat lines have been selectively bred for alcohol preference (P/NP, HAD/LAD, Li, Lumeng, \& Doolittle, 1993; Sardinian sP/sNP, Colombo, Lobina, Carai, \& Gessa, 2006; AA/ANA, Sinclair, Lê, \& Kiianmaa, 1989; and University of Chile UChA/UChB, Quintanilla, Israel, Sapag, \& Tampier, 2006). P rats readily consume 5-6 g/kg/day under oral free access to alcohol/water solutions (Murphy et al., 2002), and have been shown to exhibit a pronounced alcohol deprivation effect (ADE) with subsequent escalation of ethanol consumption (Rodd-Henricks et al., 2000). P rats have also been shown to continue to respond for oral ethanol despite increasing response requirements (Czachowski \& Samson, 2002; Ritz, Garcia, Protz, Rael, \& George, 1994). P rats therefore serve as an ideal model for human alcohol abuse and possibly an ideal strain for IV self-administration due to maintained responding for ethanol despite increasing response requirements.

Multiple schedules of reinforcement have been shown to result in independent and stable responding for each individual component of the schedule (Czachowski, Samson, \& Denning, 1999; Slawecki, Samson, \& Hodge, 1997). During a multiple-schedule session, animals are allowed access to multiple reinforcers during discrete time intervals during which only one reinforcer or reinforcer complex is available. Such a design allows for the isolation and manipulation of each schedule component.

Overall, the previous studies using IV self-administration of ethanol in rats suggest that it may be possible to maintain stable responding for ethanol by increasing the ethanol concentration and unit dose, establishing elevated reinforcer administration using a compound reinforcer of IV ethanol plus a substance known to increase responding (e.g., sucrose), and using a rat line selected for high oral ethanol consumption. These parameters 
theoretically should lead to the development of a model by which rats will self-administer ethanol intravenously to a level that would allow for examination of pertinent questions regarding human alcohol abuse. To examine the effects of these modifications of IV ethanol self-administration in rats, a two-lever choice multiple-schedule study design was performed using the selectively bred alcohol-preferring $\mathrm{P}$ rat. The initial hypothesis was that responding for the IV ethanol plus oral sucrose schedule would be more reinforcing than sucrose alone, as demonstrated by a significant increase in responding during the IV ethanol plus oral sucrose schedule compared to responding for the oral sucrose-only schedule.

\section{Methods}

\section{Subjects}

One cohort of male P rats (70th generation, Indiana University School of Medicine, Indianapolis, IN; initial weight $172 \pm 9 \mathrm{~g}$ ) was used for ethanol concentration and dose determination (see below) and eight additional P rats (71st generation, initial weight $235 \pm 9$ g) were used for the main experiment. Rats were individually housed in a controlled environment with a 12-h light/dark cycle (lights on at 8:00 AM). The animals had ad libitum access to food and water throughout the study except for a brief 5-day water deprivation period during initial lever training. All procedures were performed in accordance with NIH guidelines and IACUC approval.

\section{Apparatus}

Rat operant conditioning chambers (Coulbourn Instruments; Lehigh Valley, PA, USA) contained within sound-attenuating chambers were used for daily sessions. The front and rear walls of the chamber were composed of Plexiglas ${ }^{\circledR}$ with the side panels composed of aluminum. The right side panel contained the response panel. Retractable response levers were located on either side of a sipper spout with a stimulus light located directly above each lever. The sipper tube was located in the center of the right panel with a sensor to record lick data. Discrete dosing of fluid into the sipper tube was achieved by computer activation of a valve located on the exterior of the sound-attenuating chamber. Correct responding during sessions resulted in activation of a light and release of $0.1 \mathrm{~mL}$ solution into the sipper tube. A house light was located at the top right of the back wall. Intravenous reinforcers were delivered via a Coulbourn computer controllable infusion pump located outside of the chamber with the infusion line connected via a rotating swivel tether allowing for relatively unrestricted movement about the chamber. All relevant input and output session data were controlled and recorded on a Windows PC using Coulbourn Graphic State software.

\section{Procedures}

\section{Ethanol Concentration and Dose Determination-Prior to examination of the} reinforcer complex using the multiple-schedule study design, a preliminary assessment was performed to determine a dose and ethanol infusate concentration that would maintain responding across a session. These animals were trained to press a lever for access to an oral $10 \%$ sucrose (10S) solution on a FR1 schedule. Following acquisition of lever responding, the schedule was increased to a FR4 and the oral sucrose concentration decreased to a final 
concentration of $2 \%$ sucrose $(2 \mathrm{~S})$ over sessions. Animals were then surgically implanted with an indwelling jugular catheter and allowed 5 days to recover. Following recovery, animals performed daily 30-min sessions during which lever responding on a FR4 schedule earned access to a compound reinforcer of oral $2 \mathrm{~S}$ plus IV ethanol [6\% ethanol in halfnormal saline $(0.45 \% \mathrm{NaCl}), 10 \mathrm{mg} / \mathrm{kg} /$ injection]. Animals maintained stable session responding for 8 days (stable responding of $<20 \%$ variability in reinforcers earned between sessions). One animal was removed prior to completion of stable responding due to loss of catheter patency. The remaining animals had an average ethanol intake of $0.45 \pm 0.03 \mathrm{~g} / \mathrm{kg}$ during the 30-min operant session.

Infusate concentration was then varied between animals during a single session (10-40\% ethanol) with unit doses increased to $25 \mathrm{mg} / \mathrm{kg} /$ infusion (see Fig. 1A). Blood alcohol concentration was assessed following this 30-min session (see Fig. 1B). Tail blood samples were collected every $20 \mathrm{~min}$ beginning immediately after the 30-min session. Plasma was analyzed using the AM1 Analyzer (Analox Instruments; Lunenburg, MA, USA). From this, an infusate concentration of $20 \%$ ethanol and dose of $25 \mathrm{mg} / \mathrm{kg} /$ infusion was found to maintain lever responding across the entire session with measurable intakes and BAC and therefore was used for the multiple-schedule study to assess the contributions of the oral sucrose and IV ethanol compound reinforcer.

Multiple-Schedule Procedure-For a schematic of the experimental procedures for multiple-schedules experiments, see Fig. 2. Operant lever press responding was established during daily training sessions using an oral $5 \%$ sucrose $(5 \mathrm{~S})$ solution on a fixed ratio one (FR1) schedule. Once lever responding was acquired, the schedule was incrementally increased over sessions to a FR4 schedule. A 7-sec time-out (TO) period was added following reinforcer administration so that a consistent reinforcer duration could be established across all reinforcer types (i.e., IV infusions of 5-sec duration followed by a 2sec time-out, therefore reinforcer access time can be equated across reinforcers). Prior to surgery, the animals were briefly introduced to the second lever. Animals were trained to respond on the "other" lever for an oral $1 \mathrm{~S}$ reinforcer on a FR1 schedule while the previously paired sucrose lever was retracted. The schedule was incrementally increased to a FR4 across several sessions. This completed the training for sucrose reinforcement on both levers, and from this point on, one lever was associated with only oral reinforcers ("sucrose lever") and the other with IV reinforcer plus oral reinforcer ("IV lever"). Sucrose lever and IV lever positions were counterbalanced across animals.

After responding on a FR4 schedule was achieved for both levers, an indwelling jugular catheter was placed following standard catheterization surgery procedures (see below; Manzardo, Stein, \& Belluzi, 2002) while animals were under pentobarbital anesthesia. Following surgery, animals completed daily sessions responding for an oral $1 \mathrm{~S}$ solution on the sucrose lever for seven sessions. During the final two sessions, the animals were attached to the infusion tether to habituate the animals to the infusion-related apparatus (animals had access to an oral sucrose reinforcer with no infusions administered). Animals then had twice-daily training sessions for 7 days with only one lever extended into the chamber. During these sessions the stimulus light above the lever was paired with extension; in this and all subsequent sessions, the light indicated the active lever. The morning session 
occurred within one hour of the onset of the light portion of the light/dark cycle (07000800) and only the oral sucrose reinforcer lever was accessible. The evening session occurred within one hour of the initiation of the dark cycle (1900-2000) and only the IV lever was extended into the chamber. During the first two days of this period, the IV lever was paired with a reinforcer complex of IV normal saline $(0.9 \% \mathrm{NaCl})$ plus oral $1 \mathrm{~S}$. Following this, the IV lever was paired with a reinforcer complex of IV ethanol [20\% v/v in half-normal saline $(0.45 \% \mathrm{NaCl}), 25 \mathrm{mg} / \mathrm{kg} /$ injection] plus oral $1 \mathrm{~S}$.

Animals were then trained on the multiple schedules with daily 32-min sessions. A 2-minute wait period occurred at the initiation of each session during which time both levers were retracted. Both levers were then extended into the chamber and lever activation for reinforcer access alternated between the two reinforcer types on a fixed time interval. The cue light above each lever was on when that lever was active. Progression to the subsequent reinforcer component was independent of responding during the individual components. The initial active lever was alternated across sessions (IV ethanol-first component or oral sucrose-only first component). The multiple-schedule training started with two components, each $15 \mathrm{~min}$ in length, which progressively shortened over days to components of $7.5 \mathrm{~min}, 5$ $\mathrm{min}$, and finally $2.5 \mathrm{~min}$ in length. Animals received two sessions at each component length with IV ethanol as the first schedule following each change in component length. There was no effect noted on ethanol component responding as the component interval time shortened; therefore the 2.5-min component length was used for all subsequent testing. The criterion for stable responding under the multiple schedules was set at less than 10 "incorrect" responses (responses on the inactive lever) during each component.

Surgery-While under pentobarbital anesthesia, the prepared catheter was inserted into the right jugular vein such that the tip was located just above the right atrium (Manzardo et al., 2002). The tubing was then passed subcutaneously over the shoulder to a 1 to $2 \mathrm{~cm}$ midscapular incision. Threading of the catheter over the shoulder to the dorsal access point was facilitated by a $3-\mathrm{cm}$ incision located $4 \mathrm{~cm}$ above the right hind leg in order to diminish site damage and scar tissue formation around the dorsal catheter port. Incision sites were then sutured with non-dissolvable 4-0 surgical silk and treated with a topical antibiotic ointment. To expedite healing, both penicillin ( $0.2 \mathrm{~mL}$ IM Combi-Pen) and atropine (1.0 $\mathrm{mg} / \mathrm{kg}$ subcutaneous) were administered prior to surgery. After surgery, catheter patency was facilitated by daily administration of a heparin-gentamicin maintenance flush. Patency was assured with weekly infusions of the fast-acting barbiturate Brevital (1\% methohexital sodium). Animals with either delayed or no response were removed from the study. Animals were allowed at least 5 days to recover from surgery prior to attachment of infusion tether.

\section{Statistical Analyses}

Mean reinforcers and error responses for each schedule component were averaged across 2.5-min multiple-schedule daily sessions for "ethanol-first component" and "sucrose-first component" sessions ( 8 total days, 4 of each session type). Average total reinforcers and error responding were analyzed using a two-way within-subjects repeated measures analysis of variance (ANOVA) with session type and reinforcer as factors for within-session data. All licks that occurred within $10 \mathrm{sec}$ of reinforcer delivery (a time that should be more than 
sufficient to consume $0.1 \mathrm{~mL}$ fluid) were summed and divided by the number of reinforcers delivered for each session type to generate average licks per reinforcer. These were collapsed across days and also analyzed by two-way within-subject repeated measures ANOVA with session type and reinforcer as factors. Average component reinforcers and error responding were analyzed using a two-way within-subject repeated measures ANOVA with session and component as factors for within-session data. Post hoc comparisons were performed using Student-Newman-Keuls $t$ tests $(p<0.05)$.

\section{Results}

The study design allowed observation of the successive effect of surgery, tether attachment, IV saline, and IV ethanol on FR4 responding for 1\% sucrose (S1). One animal did not acclimate to the tether apparatus and an additional animal lost patency prior to acquiring the 2.5-min multiple schedules. Both were removed from analysis. For the six remaining animals, the calculated average ethanol intake from total session ethanol reinforcers earned across the final eight daily 30-min multiple-schedule sessions was $0.34 \pm 0.04 \mathrm{~g} / \mathrm{kg}$. The measured average ethanol intake (i.e., the actual volume delivered from the syringes/ session) was $0.47 \pm 0.04 \mathrm{~g} / \mathrm{kg}(1.10 \pm 0.12 \mathrm{~mL})$. The difference between "calculated" and actual ethanol intake is attributed to a combination of the accuracy of syringe measurement and variability in pump rate to achieve desired unit dosing. Two-way repeated measures $(\mathrm{RM})$ ANOVAs (day $\times$ reinforcer type) found no significant main effect of day for either total session reinforcers [ethanol-first component $F_{(3,12)}=1.05, p=0.44$; sucrose-first component $F_{(3,12)}=0.25, p=0.18$ ] or for total error responding [ethanol-first component $F_{(3,12)}=0.78, p=0.60$; sucrose-first component $\left.F_{(3,12)}=1.16, p=0.44\right]$. Therefore, since responding was stable across days, data were collapsed across days for each component and session type (ethanol-first component or sucrose-first component) to allow for assessment of differences in responding between components for each session type. One animal lost catheter patency on the fifth day of the 2.5-min multiple-schedule sessions, and is included in the collapsed means but only contributes four days of data rather than eight.

\section{Analysis of Correct Responding}

A significant main effect of session type (sucrose-first component versus ethanol-first component) for total session reinforcers was observed $\left[F_{(1,5)}=21.53, p=0.006\right]$ (Fig. 3A). A significant interaction between session type and reinforcer type (sucrose versus sucrose plus IV ethanol) on total session reinforcers was also observed $\left[F_{(1,5)}=22.40, p=0.005\right]$. Post hoc analysis of total reinforcers revealed a significantly greater number of total sucrose reinforcers compared with ethanol reinforcers for both sucrose-first component sessions ( $p=$ 0.003 ) and ethanol-first component sessions $(p=0.005)$. This statistically significant greater number of total sucrose reinforcers for both sucrose-first component and ethanol-first component sessions suggests a preference for sucrose-only reinforcement. Moreover, the analysis of licks indicated no effect of reinforcer $\left[F_{(1,5)}=0.03, p=0.87\right]$ or session type $\left[F_{(1,5)}=2.35, p=0.19\right]$. This confirmed that rats were consuming the sucrose similarly each time it was delivered into the sipper tube both when IV ethanol was and was not paired with it (i.e., there appeared to be no negative effect of any possible "taste" of the IV ethanol) and 
that the solution was completely consumed following each delivery regardless of session type.

A significant main effect of session type was also observed across components for correct responses $\left.\left[F_{(1,55)}=12.11, p<0.001\right)\right]$ (Figs. $4 \mathrm{~A}$ and $4 \mathrm{~B}$ ). As well, a significant interaction between session type and component was observed $\left[F_{(11,55)}=13.07, p<0.001\right]$. Post hoc analysis of reinforcers revealed a significantly greater number of correct responses on the sucrose lever with sucrose-first component sessions (1st component versus 3rd component, $p<0.001)$. A significantly greater number of correct responses on the sucrose lever as compared with correct responses on the IV lever was observed for the first seven components [with the exception of the fourth component] when compared between session types (Fig. 5A). This greater number of total sucrose reinforcers, first-component sucrose responses (during sucrose-first component sessions), and correct sucrose responses during the first half of the session suggests a preference for the sucrose-only reinforcer despite sucrose availability during IV ethanol component.

\section{Analysis of Error Responding}

A significant main effect of reinforcer type was shown for total session error responding $\left[F_{(1,5)}=16.37, p=0.01\right]$ (Fig. 3B), with no interaction between session type and reinforcer type $\left[F_{(1,5)}=0.14, p=0.72\right]$. A significant main effect of session type was observed across components for error responses $\left.\left[F_{(1,55)}=4.88, p<0.001\right)\right]$ (Fig. 5B). As well, a significant interaction between session type and component was observed $\left[F_{(11,55)}=5.55, p<0.001\right]$. Post hoc analysis of error responding revealed significantly greater error responding on the sucrose lever compared with the IV lever for the first six components when compared between session types (Fig. 5B). This greater number of both total session sucrose-error responding and sucrose-lever error responding during the first six components suggests a persistence in responding for the oral sucrose-only despite availability of oral sucrose with the IV ethanol component.

\section{Discussion}

In light of the long history of difficulties achieving IV ethanol self-administration in the rat, we attempted to combine multiple factors (use of the alcohol-preferring P rat, moderately high ethanol concentration/dose, and a compound sucrose/ethanol reinforcer) that were thought to be likely issues limiting the success of previous paradigms. We found that lever responding was stable across days for both oral sucrose and oral sucrose plus IV ethanol. However, correct responding during sucrose-only components was consistently higher than during sucrose/ethanol components and error responding was higher on the sucrose lever during sucrose/ethanol components than on the sucrose/ethanol lever during sucrose components, regardless of session type (sucrose-first vs. ethanol-first). Although the use of the multiple schedules precludes a direct analysis of animal "preference" for the individual reinforcers, the greater error responding on the sucrose lever suggests that, despite oral sucrose also being available during the sucrose plus IV ethanol components, the animals persisted in responding for access to sucrose only. This indicates either an incomplete acquisition of the multiple-schedule response requirements or a "preference" for the sucrose- 
only reinforcer. Although it is possible that the animals did not completely acquire the response requirements for the multiple schedule, the prolonged stability in responding across days suggests that animals did acquire proper responding for both components of the multiple schedules. As well, error responding on the ethanol lever was below the ceiling criteria for stable responding (i.e., less than 10 error responses per component) for all components except for component 3 during the sucrose-first sessions (Fig. 5B). Though incomplete acquisition of responding for the multiple schedules cannot be completely ruled out, the error responding appears more likely an indication of a degree of "preference" for sucrose alone over the sucrose plus IV ethanol.

Since the same sucrose concentration is available with both schedules, variations in responding should reflect the role of IV ethanol as a reinforcer. If responding during the IV components remained equal to the response rate of the sucrose-only components, then IV ethanol is neither reinforcing nor aversive. However, if responding during the IV components decreased, IV ethanol would be shown to have aversive or punishing qualities. Interestingly, first component responding on the IV lever was only marginally decreased from the subsequent sucrose responding during sessions when ethanol was the first component of the multiple schedule. However, during sucrose-first component sessions, first-component sucrose responding was significantly higher compared to responding during any other component (see Fig. 5A). Taken as a whole, these findings (greater sucrose-only reinforcers earned, greater sucrose-lever error responding, and greater first-component responding for sucrose) suggest that the IV administration of ethanol was aversive. The slight elevation in responding noted when ethanol was available first may just reflect the motivation to consume sucrose when it was first available while tolerating the IV ethanol.

Grupp \& Stewart (1983) sought to specifically examine the aversive properties of IV ethanol using an active avoidance procedure. Wistar rats were trained to jump over a hurdle to avoid receiving an IV infusion of ethanol. The rats actively avoided exposure to ethanol doses of $0.2,0.4$, and $0.8 \mathrm{~g} / \mathrm{kg}$. They also investigated whether rats would actively self-administer IV ethanol using a runway paradigm and a 30-sec infusion of either saline or ethanol in the goal box. For all ethanol doses tested, the rats would passively avoid IV ethanol exposure by not entering the goal box after several trials. This active and passive avoidance to IV ethanol administration suggests that IV ethanol acts as a punisher in rats. It is currently unclear if the aversion to IV ethanol is due to the peripheral (e.g., discomfort due to infusate to body temperature difference and baroreceptor response to venous supply dilution) or due to central effects of ethanol (i.e., rapid ethanol brain exposure).

The responding observed during the present study resembles responding typically observed during conflict or punishment testing. Conflict or punishment testing examines the effect on responding when opposing motivations are presented concurrently (Commissaris \& Fontana, 1992). That is, conflict testing examines responding for a reinforcer with both positive qualities and aversive qualities. Conflict testing is readily demonstrated by allowing a foodrestricted animal to respond for access to a compound reinforcer of food plus foot shock. Though the animals in the current study were not food deprived, the perseveration on the sucrose lever during the sucrose plus IV ethanol components suggests a conflict of "wanting" the oral sucrose reinforcement without the administration of IV ethanol. This is 
also demonstrated by the greater first-component sucrose responding when sucrose-only is the first reinforcer. If IV ethanol administration is aversive, it is probable that the ethanol intake observed in this study was predominantly driven by responding for the sucrose portion of the IV ethanol plus sucrose compound reinforcer rather than the ethanol. However, if sucrose alone was driving responding and IV ethanol was highly aversive, one would expect food- and water-sated animals, such as those used in this study, to extinguish responding during the IV ethanol component and shift all responding to the non-aversive sucrose-only component. Such extinction of IV ethanol responding was not observed. All animals maintained responding during the IV ethanol components, suggesting again that the IV ethanol was "tolerated" but not preferred when sucrose was available (similar to the responding observed in the pilot experiment where sucrose was only available when IV ethanol was administered; Fig. 1A). In addition, while it cannot be ruled out that the initial training exclusively on the sucrose-only lever may have produced some preference for that lever, again the pattern of continued responding during the IV ethanol component provides evidence against this being the only determinant of lever choice. Finally, while it could be argued that rats achieved the "desired" ethanol dose and then stopped responding, this seems unlikely given that they continued to earn comparable sucrose and ethanol reinforcers over the final five components of the session.

Overall, this study demonstrates that the use of a compound reinforcer of $1 \%$ oral sucrose plus $20 \%$ IV ethanol does not override the aversive properties of IV ethanol administration, even in the ethanol-preferring P rat. The data suggest that the animals were responding primarily for access to the oral sucrose component rather than access to either the IV ethanol component or reinforcer complex. The lower responding for IV ethanol suggests that the IV ethanol was at least somewhat aversive, even though the concentration of ethanol used is one that is self-administered in mice. Thus, a method by which rats will intravenously selfadminister ethanol with responding driven by the reinforcing effects of ethanol remains elusive. Further work attempting to establish a viable method by which rats will selfadminister ethanol IV must address the aversive effects of the IV route as well as demonstrate a preference for IV ethanol.

\section{Acknowledgments}

IUPUI Developing Diverse Researchers with InVestigative Expertise (DRIVE) grant from IUPUI to AEK; T32AA007462 and R01AA016101 from NIAAA to CLC; and P60AA007611 from NIAAA.

\section{References}

Blokhina EA, Dravolina OA, Bespalov AY, Balster RL, Zvartau EE. Intravenous self-administration of abused solvents and anesthetics in mice. European Journal of Pharmacology. 2004; 485:211-218. [PubMed: 14757143]

Colombo G, Lobina C, Carai MA, Gessa GL. Phenotypic characterization of genetically selected Sardinian alcohol-preferring (sP) and -non-preferring (sNP) rats. Addiction Biology. 2006; 11:324338. [PubMed: 16961762]

Commissaris, RL.; Fontana, DJ. Pharmacological evaluation of potential animal models for the study of antipanic and panicogenic treatment effects. In: Boulton, AA.; Baker, GB.; Martin-Iverson, MT., editors. Neuromethods, Vol. 19: Animal Models in Psychiatry, II. Clifton, NJ: Humana Press; 1992. p. $199-232$. 
Czachowski CL, Samson HH. Ethanol- and sucrose-reinforced appetitive and consummatory responding in HAD1, HAD2, and P rats. Alcoholism: Clinical and Experimental Research. 2002; 26:1653-1661.

Czachowski CL, Samson HH, Denning CE. Independent ethanol- and sucrose-maintained responding on a multiple schedule of reinforcement. Alcoholism: Clinical and Experimental Research. 1999; 23:398-403.

Gass JT, Olive MF. Reinstatement of ethanol-seeking behavior following intravenous selfadministration in Wistar rats. Alcoholism: Clinical and Experimental Research. 2007; 31:14411445.

Grahame NJ, Cunningham CL. Intravenous ethanol self-administration in C57BL/6J and DBA/2J mice. Alcoholism: Clinical and Experimental Research. 1997; 21:56-62.

Grahame NJ, Low MJ, Cunningham CL. Intravenous self-administration of ethanol in beta-endorphindeficient mice. Alcoholism: Clinical and Experimental Research. 1998; 22:1093-1098.

Grupp LA, Stewart RB. Active and passive avoidance behaviour in rats produced by IV infusions of ethanol. Psychopharmacology. 1983; 79:318-321. [PubMed: 6407045]

Hyytiä P, Schulteis G, Koob GF. Intravenous heroin and ethanol self-administration by alcoholpreferring AA and alcohol-avoiding ANA rats. Psychopharmacology. 1996; 125:248-254. [PubMed: 8815960]

Ikegami A, Olsen CM, Fleming SM, Guerra EE, Bittner MA, Wagner J, et al. Intravenous ethanol/ cocaine self-administration initiates high intake of intravenous ethanol alone. Pharmacology, Biochemistry, and Behavior. 2002; 72:787-794.

Karoly AJ, Winger G, Ikomi F, Woods JH. The reinforcing property of ethanol in the rhesus monkey II. Some variables related to the maintenance of intravenous ethanol-reinforced responding. Psychopharmacology. 1978; 58:19-25. [PubMed: 97716]

Kelley BM, Bandy AL, Middaugh LD. A study examining intravenous ethanol-conditioned place preference in C57BL/6J mice. Alcoholism: Clinical and Experimental Research. 1997; 21:16611666.

Li TK, Lumeng L, Doolittle DP. Selective breeding for alcohol preference and associated responses. Behavior Genetics. 1993; 23:163-170. [PubMed: 8099788]

Lyness WH, Smith FL. Influence of dopaminergic and serotonergic neurons on intravenous ethanol self-administration in the rat. Pharmacology, Biochemistry, and Behavior. 1992; 42:187-192.

Manzardo AM, Stein L, Belluzzi JD. Rats prefer cocaine over nicotine in a two-lever selfadministration choice test. Brain Research. 2002; 924:10-19. [PubMed: 11743990]

Murphy JM, Stewart RB, Bell RL, Badia-Elder NE, Carr LG, McBride WJ, et al. Phenotypic and genotypic characterization of the Indiana University rat lines selectively bred for high and low alcohol preference. Behavior Genetics. 2002; 32:363-388. [PubMed: 12405517]

Numan R. Multiple exposures to ethanol facilitate intravenous self-administration of ethanol by rats. Pharmacology, Biochemistry, and Behavior. 1981; 15:101-108.

Oei TP, Singer G. Effects of a fixed time schedule and body weight on ethanol self-administration. Pharmacology, Biochemistry, and Behavior. 1979; 10:767-770.

Quintanilla ME, Israel Y, Sapag A, Tampier L. The UChA and UChB rat lines: metabolic and genetic differences influencing ethanol intake. Addiction Biology. 2006; 11:310-323. [PubMed: 16961761]

Ritz MC, Garcia JM, Protz D, Rael AM, George FR. Ethanol-reinforced behavior in P, NP, HAD and LAD rats: differential genetic regulation of reinforcement and motivation. Behavioural Pharmacology. 1994; 5:521-531. [PubMed: 11224304]

Rodd-Henricks ZA, McKinzie DL, Shaikh SR, Murphy JM, McBride WJ, Lumeng L, et al. Alcohol deprivation effect is prolonged in the alcohol preferring $(\mathrm{P})$ rat after repeated deprivations. Alcoholism: Clinical and Experimental Research. 2000; 24:8-16.

Sinclair JD, Lê AD, Kiianmaa K. The AA and ANA rat lines, selected for differences in voluntary alcohol consumption. Experientia. 1989; 45:798-805. [PubMed: 2673834]

Sinden JD, Le Magnen J. Parameters of low-dose ethanol intravenous self-administration in the rat. Pharmacology, Biochemistry, and Behavior. 1982; 16:181-183. 
Slawecki CJ, Samson HH, Hodge CW. Differential changes in sucrose/ethanol and sucrose maintained responding by independently altering ethanol or sucrose concentration. Alcoholism: Clinical and Experimental Research. 1997; 21:250-260.

Smith SG, Davis WM. Intravenous alcohol self-administration in the rat. Pharmacological Research Communications. 1974; 6:379-402. [PubMed: 4474673]

Thomsen M, Caine SB. Intravenous drug self-administration in mice: practical considerations. Behavior Genetics. 2007; 37:101-118. [PubMed: 17226102]

Williams KL, Broadbear JH, Woods JH. Noncontingent and response-contingent intravenous ethanol attenuates the effect of naltrexone on hypothalamic-pituitary-adrenal activity in rhesus monkeys. Alcoholism: Clinical and Experimental Research. 2004; 28:566-571.

Zimmermann US, Mick I, Laucht M, Vitvitskiy V, Plawecki MH, Mann KF, et al. Offspring of parents with an alcohol use disorder prefer higher levels of brain alcohol exposure in experiments involving computer-assisted self-infusion of ethanol (CASE). Psychopharmacology. 2009; 202:689-697. [PubMed: 18936917]

Zimmermann US, Mick I, Vitvitskyi V, Plawecki MH, Mann KF, O'Connor S. Development and pilot validation of computer-assisted self-infusion of ethanol (CASE): a new method to study alcohol self-administration in humans. Alcoholism: Clinical and Experimental Research. 2008; 32:13211328. 


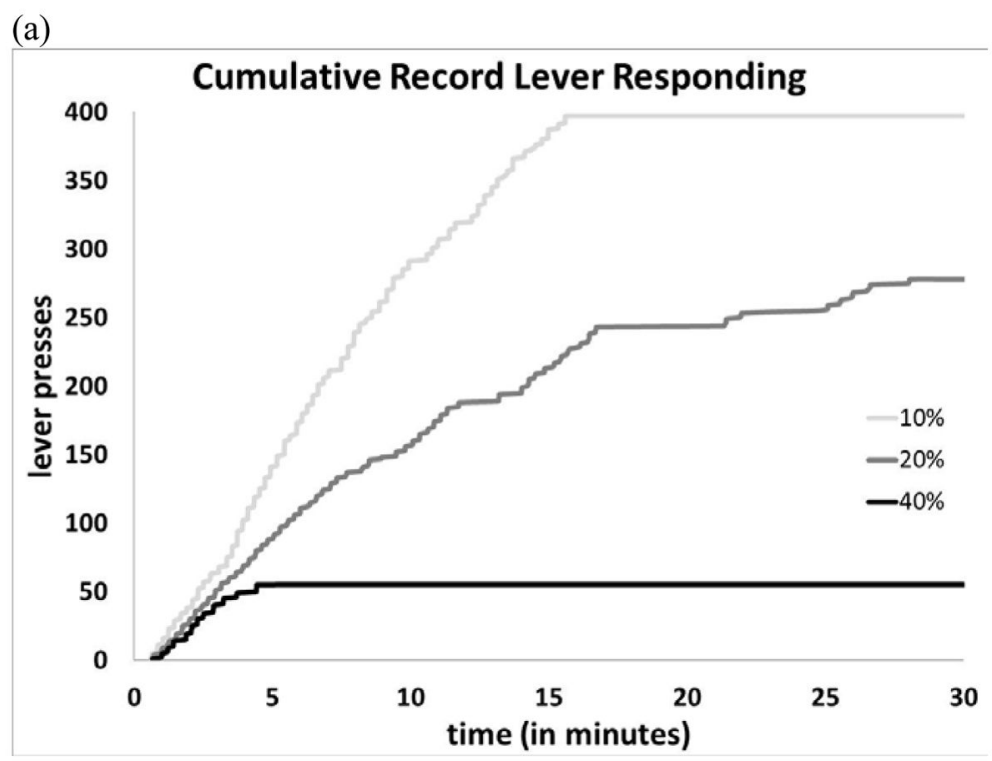

(b)

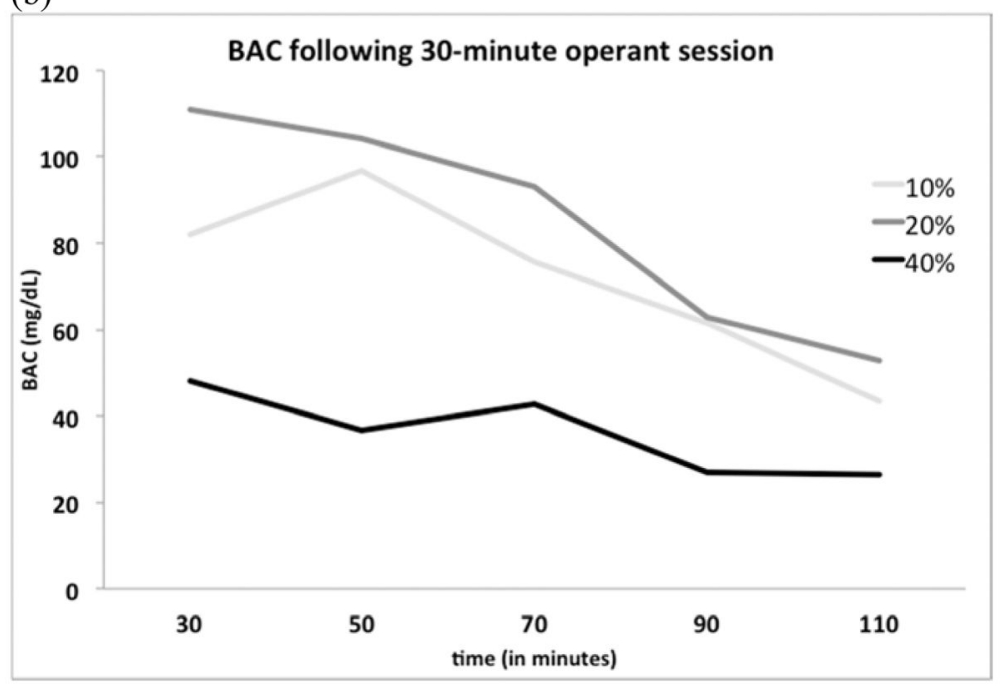

Figure 1.

Preliminary assessment of varied ethanol concentrations. (a) Cumulative record for lever responding during a 30-min session for individual animals $(n=3)$ with various ethanol infusate concentrations. (b) Blood alcohol concentrations following 30-min selfadministration sessions for individual rats with varying ethanol infusate concentrations. 


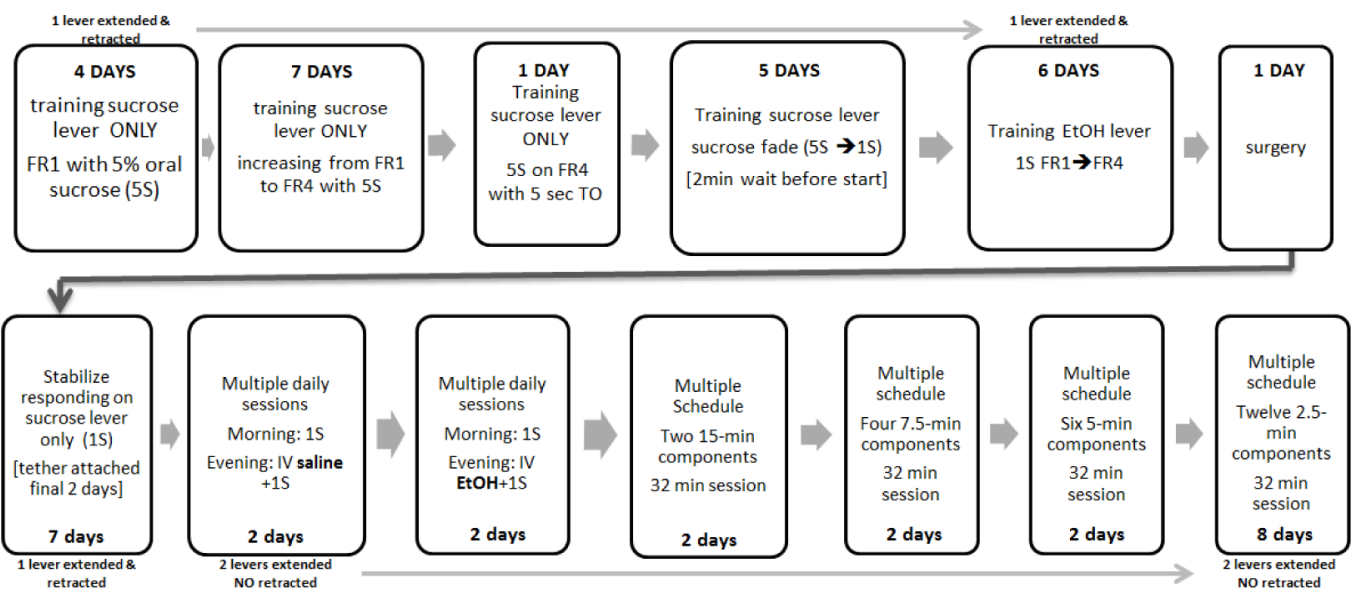

Figure 2.

Time Table for Multiple Schedule Training 
(a)

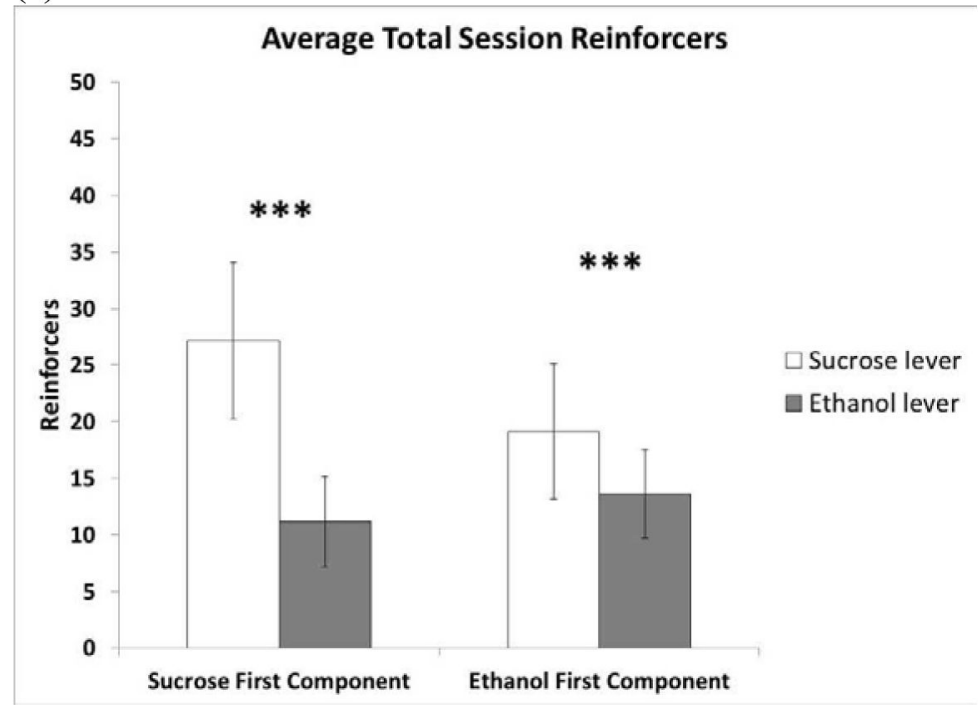

(b)

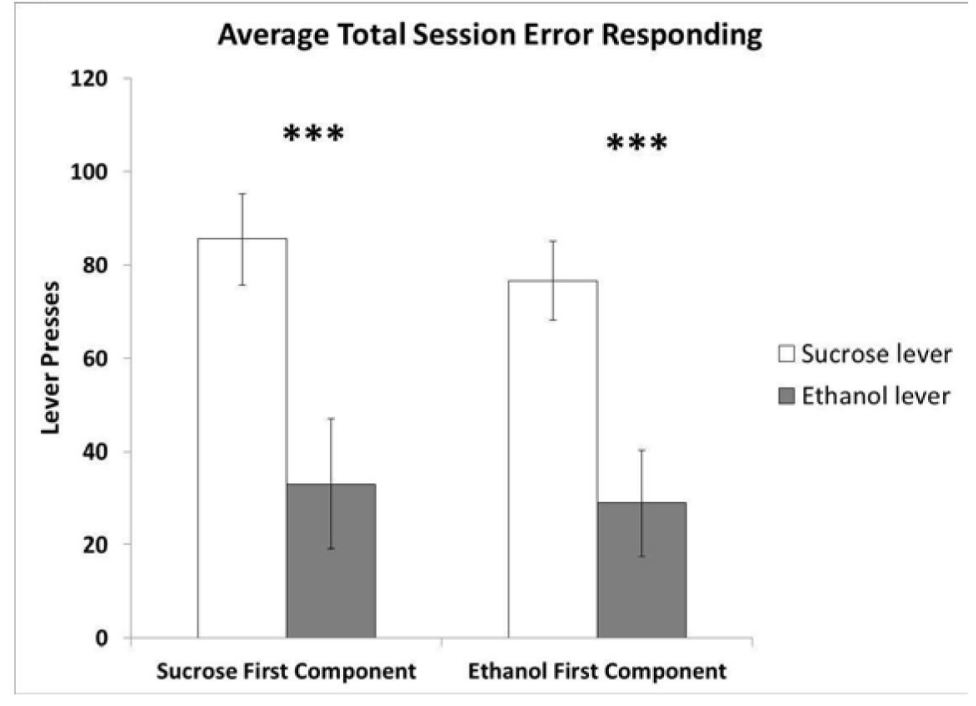

Figure 3.

Average total session correct (a) and error responding (b) for sucrose only (open bars) and IV ethanol plus oral sucrose (shaded bars). On the left are the data for the sucrose-first component sessions while the data for the ethanol-first component sessions are on the right. A statistically significant difference was noted for reinforcer type during sucrose-first component sessions for average total reinforcers $(p<0.01)$ and error responding $(p=0.01)$. As well, a statistically significant difference in reinforcer type was noted for ethanol-first component sessions for total average reinforcers and total error responding $(p<0.01)$. *** $p$ $<0.01$. Data are presented as mean \pm SEM. 


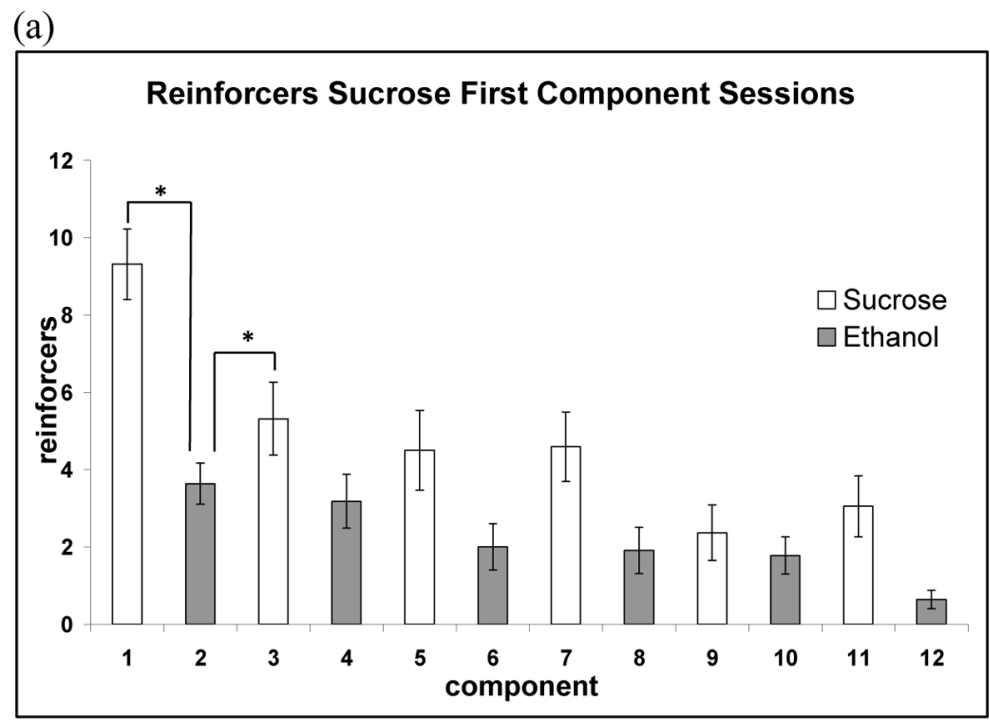

(b)

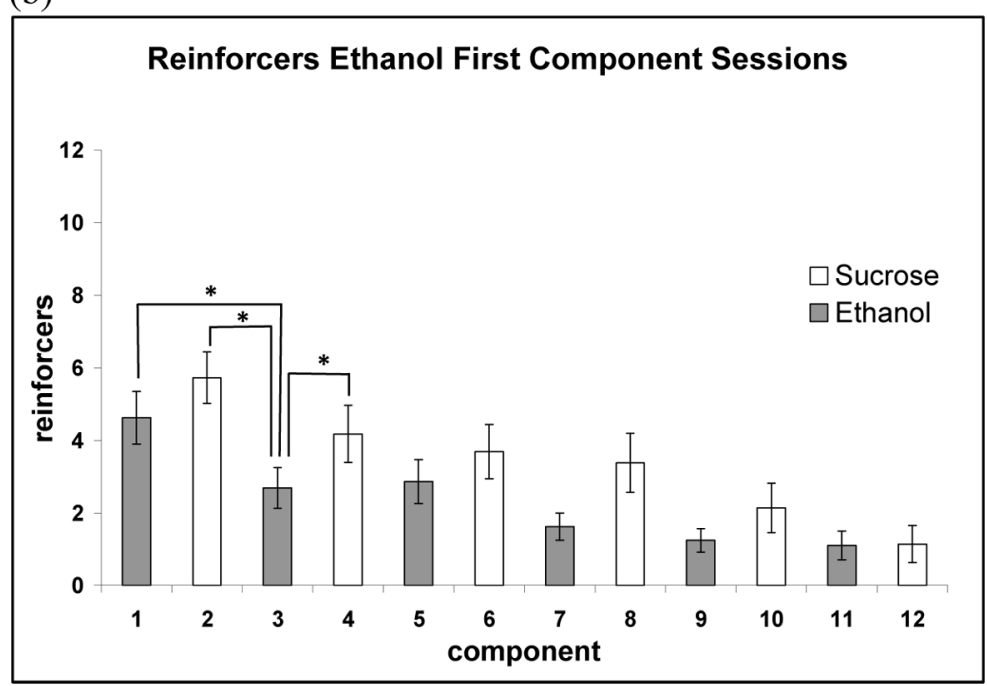

Figure 4.

Average reinforcers administered during sucrose-first component (a) and ethanol-first component (b) sessions. During sucrose-first component sessions (a), there was a significant difference between the first ethanol component and the first and second sucrose components. There was also a significant difference between the first ethanol component and the subsequent ethanol component during ethanol-first component sessions (b) indicating a substantial drop in responding between the first and second ethanol schedule components. $*_{p}<0.05$. Data are presented as mean \pm SEM. 
(a)

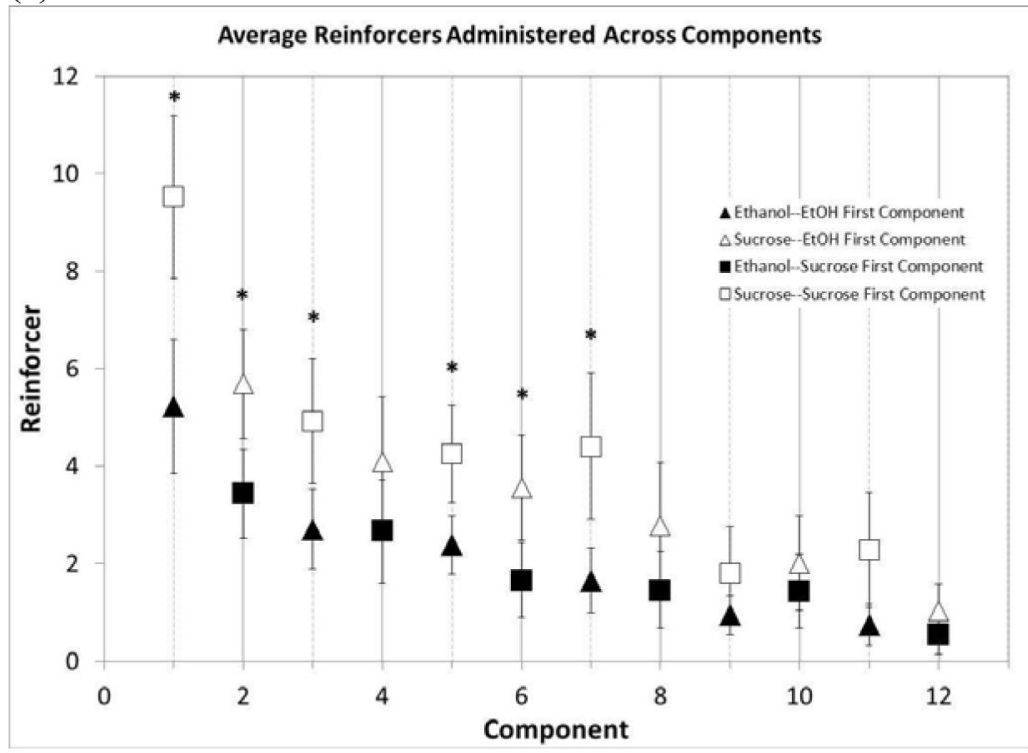

(b)

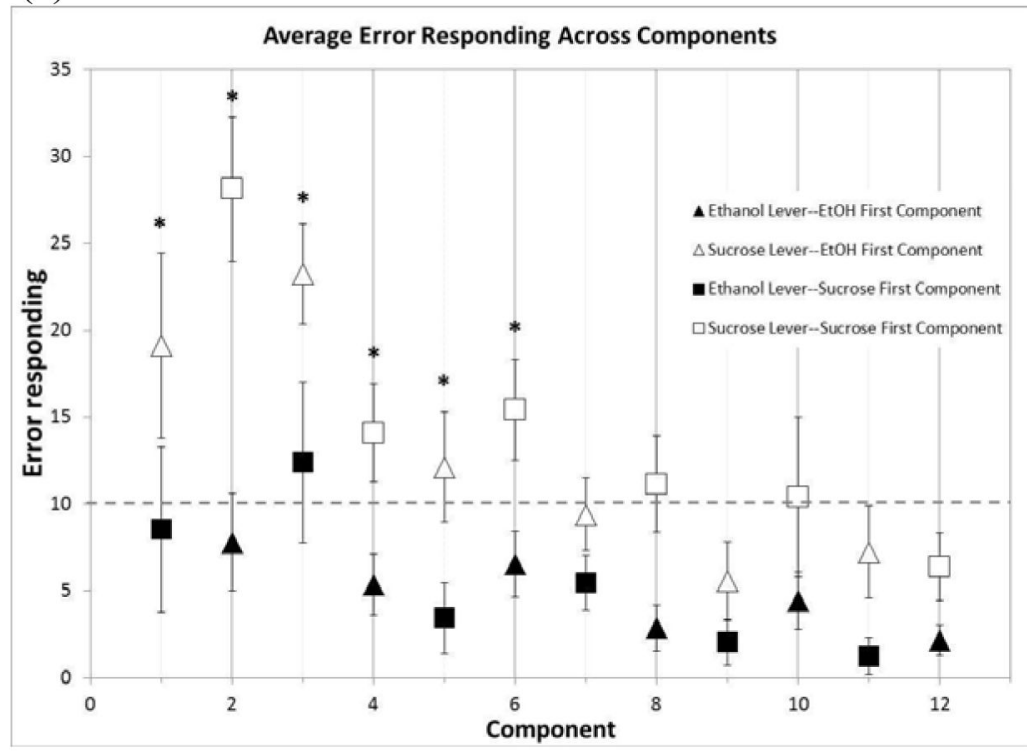

Figure 5.

Reinforcer administration (a) and error responding (b) for sucrose-first component and ethanol-first component sessions across components. The shading indicates reinforcer type (filled for ethanol, open for sucrose). The triangles show responding during ethanol-first component sessions and the squares show responding during sucrose-first component sessions. The dashed line indicates the criterion for stable responding on multiple schedule ( $<10$ error responses/component). A significantly greater number of sucrose reinforcers compared to IV ethanol plus oral sucrose reinforcers $(p<0.05)$ (a) is noted for the first seven components (except for component 4 ). As well, a significantly greater number of 
sucrose-lever error responses $(p<0.05)(b)$ is noted for the first six components. ${ }^{*} p<0.05$. $* * \mathrm{p}<0.001$. Data are presented as mean \pm SEM. 